\title{
Estabilidade produtiva de cultivares de mandioca-de-mesa coletadas no Estado do Paraná
}

\section{Yield stability of sweet cassava cultivars from Paraná State}

\author{
Pedro Soares Vidigal Filho ${ }^{1 *}$; Manoel Genildo Pequeno ${ }^{2}$; \\ Marcus Vinícius Kvitschal ${ }^{3}$; Fabrício Rimoldi ${ }^{4}$; \\ Maria Celeste Gonçalves-Vidigal ${ }^{5}$; Gisele Cristina Zuin ${ }^{6}$
}

\section{Resumo}

O presente trabalho teve como objetivo avaliar a estabilidade de produção de raízes tuberosas e de índice de colheita de 14 cultivares de mandioca-de-mesa coletadas no Estado do Paraná. Os experimentos foram instalados nos municípios de Maringá (2001/2002 e 2002/2003) e de Campo Mourão (2003/2004 e 2004/2005), região Noroeste do Paraná, perfazendo um total de quatro ambientes. O delineamento experimental utilizado foi o de blocos completos casualizados, com três repetições. A estabilidade foi avaliada por meio das metodologias propostas por Lin e Binns, Eskridge e Annicchiarico. Em geral, as cultivares Caipira, Fécula Branca e Amarela 2 mostraram-se mais estáveis e apresentaram elevadas médias de produção de raízes tuberosas e de índice de colheita. Estas cultivares são boas indicações para cultivo na região Noroeste do Paraná também pelos baixos níveis de HCN, reduzido tempo de cozimento e boa resistência às doenças.

Palavras-chave: Mandioca-de-mesa, adaptabilidade, produção de raízes tuberosas, índice de colheita

\begin{abstract}
The objective of this work was to study the storage roots yield and harvest index stability of 14 sweet cassava cultivars collected from Paraná State. Trials were carried out in Maringá (2001/2002 and 2002/ 2003) and Campo Mourão (2003/2004 and 2004/2005) counties, Northwest region of Paraná State, making a total of four environments. Randomized complete blocks design with three replications was used. The stability was evaluated according methods proposed by Lin e Binns, Eskridge and Annicchiarico. The Caipira, Fécula Branca and Amarela 2 cultivars were the most stable cultivars and showed high storage roots yield and harvest index averages. These cultivars may be a good crop choice in Northwestern region of Paraná State because they also presented low content of HCN, fast cooking time and high level of diseases resistance.
\end{abstract}

Key words: Sweet-cassava, adaptability, storage roots yield, harvest index

\footnotetext{
1 Professor Associado do Departamento de Agronomia da Universidade Estadual de Maringá (UEM), E-mail: psvfilho@uem.br.

2 Professor Colaborador do Departamento de Agronomia da Universidade Estadual de Maringá (UEM).

3 Aluno de Doutorado no curso de Pós-graduação em Genética e Melhoramento da Universidade Estadual de Maringá (UEM).

4 Eng $^{\circ}$ Agr $^{\circ}$ Dr. pela Universidade Estadual de Maringá (UEM).

5 Professora Titular do Departamento de Agronomia da Universidade Estadual de Maringá (UEM).

6 Aluna de mestrado no curso de Pós-graduação em Genética e Melhoramento da Universidade Estadual de Maringá (UEM).

* Autor para correspondência
} 


\section{Introdução}

A planta da mandioca (Manihot esculenta Crantz) pode ser aproveitada integralmente, tanto na alimentação humana como animal (FUKUDA; IGLESIAS; SILVA, 2003). Entretanto, as raízes tuberosas ricas em amido representam a maior porção do valor econômico da planta, as quais podem ser utilizadas para os mais diversos fins, principalmente como matéria-prima para as indústrias de farinha e de fécula (LORENZI, 2003).

O Estado do Paraná é o terceiro produtor brasileiro de raízes tuberosas de mandioca (ASSOCIAÇÃO BRASILEIRA DE PRODUTORES DE AMIDO DE MANDIOCA, 2006) sendo a produção paranaense mais concentrada nas regiões Noroeste, Centro Oeste e Oeste (FONSECA JÚNIOR et al., 2002). Embora o grande volume de raízes tuberosas produzidas no Paraná seja destinado basicamente à utilização industrial, tem sido observado um crescimento no consumo de mandioca-de-mesa na forma de raízes tuberosas in natura (OTSUBO; MERCANTE; MARTINS, 2002).

A mandioca-de-mesa caracteriza-se por apresentar níveis de ácido cianídrico ( $\mathrm{HCN})$ abaixo de $100 \mathrm{mg} \mathrm{Kg}^{-1}$ de polpa crua das suas raízes tuberosas, o que permite ao consumidor se alimentar de suas raízes sem sofrer intoxicação por HCN (LORENZI; DIAS, 1993). No melhoramento de mandioca para o consumo in natura, é importante salientar que as cultivares devem apresentar bom desempenho agrícola, baixo potencial cianogênico, elevado teor de amido nas raízes tuberosas e cozimento rápido (VALLE et al., 2004).

A mandioca apresenta ampla variabilidade genética decorrente da facilidade de polinização cruzada e da elevada heterozigose natural da espécie, acarretando o surgimento de uma infinidade de novos clones naturalmente mediante a germinação de suas sementes (FUKUDA, 1986). Esta grande variabilidade genotípica natural da mandioca é de extrema importância para os programas de melhoramento, visto que estes se fundamentam na seleção de genótipos superiores, a qual só é efetiva se houver variabilidade genética disponível (MONTALVÁN; FARIA, 1999).

Em função desta ampla diversidade genética disponível no conjunto gênico, a mandioca é capaz de se adaptar às mais diferentes condições edafoclimáticas. Ao mesmo tempo, a mandioca apresenta um elevado efeito de interação entre genótipos e ambientes ( $\mathrm{G} \times \mathrm{A})$, indicando que um mesmo genótipo dificilmente se comporta de maneira semelhante em ambientes contrastantes (FUKUDA; IGLESIAS; SILVA, 2003).

Alguns trabalhos de avaliação do comportamento fenotípico de novos clones tem sido desenvolvidos no Paraná, embora a maior parte destes trabalhos tenha sido direcionado às indústrias de fécula e de farinha das regiões Norte e Noroeste do Estado. Ao avaliar nove cultivares de mandioca para indústria Vidigal Filho et al. (2000) indicaram a exploração da cultivar Fécula Branca na região Noroeste do Paraná, visto que a mesma apresentou elevada produtividade de raízes tuberosas, resistência à bacteriose e elevado teor de amido nas suas raízes tuberosas. Em trabalhos semelhantes, conduzidos nos municípios de Rolândia e de Maringá, Rimoldi et al. (2002; 2003a) verificaram que a cultivar Fibra, e os clones IAC 163-85 e IAC 45-85 apresentaram elevada produção de raízes tuberosas, bem como elevada estabilidade produtiva nos quatro ambientes de avaliação. Rimoldi et al. (2003b) observaram que os clones IAC 169-86 e IAC 47-86 mostraram boa estabilidade produtiva e baixos níveis de incidência de bacteriose em avaliações realizadas na região Noroeste do Paraná. Kvitschal et al. (2003) reportaram que o clone IAC 46-90 se destacou pela elevada produção de raízes tuberosas e de matéria seca nas suas raízes tuberosas, bem como pela baixa incidência de bacteriose e de superalongamento. Mediante o uso da análise AMMI, Kvitschal et al. (2007) reportaram que o clone IAC 190-89 mostrou elevada estabilidade para a característica produção de raízes tuberosas, além de ter apresentado baixa incidência de bacteriose e superalongamento. 
Para as cultivares de mandioca-de-mesa, tem sido dedicada mais atenção à avaliação de características culinárias, toxidade por $\mathrm{HCN}$ e resistência à deterioração fisiológica do que ao estudo dos efeitos da interação $\mathrm{G}$ x A e da estabilidade fenotípica de características agronômicas importantes, tais como produção de raízes tuberosas e índice de colheita.

As cultivares de mandioca-de-mesa Iapar 19Pioneira, Catarina Branca, Catarina Amarela, IAC 576-70 e Paulistinha apresentam ampla adaptação no Estado do Paraná (MIRANDA, 2000), no entanto, há pouca informação referente ao efeito da interação G x A e da estabilidade produtiva de cultivares de mandioca-de-mesa. Assim, o presente estudo teve como objetivo avaliar a estabilidade fenotípica de 14 cultivares de mandioca-de-mesa obtidas nas regiões Norte, Noroeste e Oeste do Paraná.

\section{Material e Métodos}

A coleta do material de propagação de 14 cultivares tradicionais de mandioca-de-mesa foi realizada durante o ano de 2001, em pequenas e médias propriedades rurais localizadas nas regiões Norte, Noroeste e Oeste do Estado do Paraná. Estas cultivares foram denominadas de Caipira, Branca 1, Quarenta Quilos, Guaíra, Amarela da Rama Branca, Amarela da Rama Cinza, Branca de Maringá, Branca 2, Amarela de São Domingos, Branca 3, Pão, Amarela 1, Fécula Branca e Amarela 2, de forma que a nomenclatura adotada foi àquela tradicionalmente utilizada pelos produtores rurais detentores das respectivas cultivares.

Os experimentos foram instalados nos municípios de Maringá (Fazenda Experimental da Universidade Estadual de Maringá) nos anos agrícolas de 2001/ 2002 e 2002/2003, e de Campo Mourão (área experimental do Integrado Colégio e Faculdade) nos anos agrícolas de 2003/2004 e 2004/2005. O clima de Maringá é do tipo Cw'h, enquanto o de Campo Mourão é do tipo Cfa, conforme a classificação de Köppen. Essa região é característica em apresentar clima mesotérmico úmido, com estação quente e chuvosa no verão, e com temperaturas mais amenas e estação chuvosa no outono (GODOY et al., 1976). A unidade de solo predominante na área experimental de Maringá é o Latossolo Vermelho distrófico, enquanto que em Campo Mourão é o Latossolo Vermelho distroférrico (EMBRAPA, 1999).

As ramas foram inicialmente seccionadas em segmentos de 0,15 a $0,20 \mathrm{~m}$ de comprimento (manivas) com auxílio de serra circular e então distribuídas, na posição horizontal, em covas de aproximadamente $0,10 \mathrm{~m}$ de profundidade. $O$ plantio dos experimentos foi realizado sempre na primeira quinzena do mês de outubro de cada ano agrícola (2001/2002, 2002/2003, 2003/2004 e 2004/2005), tendo sido adotado o sistema de preparo mínimo do solo. O preparo mínimo do solo foi realizado por meio de arado descompactador Ikeda, Modelo DP-220 M. Por sua vez, os tratos culturais e a adubação aplicada aos experimentos foram realizados conforme Lorenzi e Dias (1993).

As unidades experimentais constituíram-se de 4 fileiras de plantas com $8,0 \mathrm{~m}$ de comprimento, espaçadas a 1,0 m, e com espaçamento de $0,80 \mathrm{~m}$ entre plantas. A área útil da parcela foi composta pelas duas fileiras centrais, eliminando-se $0,80 \mathrm{~m}$ das extremidades, perfazendo um total de $12,80 \mathrm{~m}^{2} \mathrm{com}$ 16 plantas, totalizando uma população de 12.500 plantas $\mathrm{ha}^{-1}$. O delineamento utilizado foi o de blocos completos casualizados, com três repetições.

Por ocasião da colheita, realizada aos 9 meses após a emergência das plantas (mês de julho), procedeu-se a avaliação da produção de raízes tuberosas $\left(\mathrm{t} \mathrm{ha}^{-1}\right)$ e de parte aérea $\left(\mathrm{t} \mathrm{ha}^{-1}\right)$. Os dados referentes à produção de parte aérea foram utilizados no cálculo do índice de colheita (\%), que foi estimado pela razão entre o peso das raízes tuberosas produzida pela planta e o peso total da planta (produção de raízes tuberosas + produção de parte aérea), sendo posteriormente multiplicado por 100 para converter os valores em escala de porcentagem (KAWANO, 1978). 
Os dados experimentais foram submetidos à análise de variância simples e conjunta, a fim de verificar a presença de diferenças significativas para tratamentos, ambientes e de interação $\mathrm{G}$ x A (PIMENTEL GOMES, 1990), considerando efeito fixo para cultivares e efeito aleatório para ambientes. As médias das características avaliadas foram comparadas pelo teste de Scott e Knott (1974) a 5\% de probabilidade de erro. A estabilidade e a adaptabilidade fenotípica foram avaliadas mediante a aplicação das metodologias de Lin e Binns (1988), Eskridge (1990) e Annicchiarico (1992) aos dados produção de raízes tuberosas e de índice de colheita.

A metodologia proposta por Lin e Binns (1988) é baseada em métodos não paramétricos, e não apresenta as limitações que decorrem sobre as metodologias baseadas em regressão linear (FINLAY; WILKINSON, 1963; EBERHART; RUSSELL, 1966) que são dependência entre o índice ambiental e as médias do conjunto genotípico avaliado, e o risco da falta de ajuste de modelo linear ao conjunto de dados. Esses fatores têm contribuído muito para o desuso destas metodologias baseadas em análise de regressão linear. Por sua vez, a metodologia de Lin e Binns (1988) tem se mostrado apta na seleção de uma ou mais cultivares estáveis e com elevadas médias de produtividade em um amplo espectro de ambientes contrastantes. A estabilidade é avaliada pelo parâmetro $P_{i}$, o qual corresponde à soma dos desvios genéticos e dos desvios da interação $\mathrm{G}$ x A. $\mathrm{O}$ respectivo modelo pode ser expresso por:

$$
P_{i}=\left[\left(\frac{a\left(\overline{Y_{i .}}-\bar{M}\right)^{2}}{2 a}\right)+\left(\sum_{j=1}^{a} \frac{\left(Y_{i j}-\bar{Y}_{i .}-\bar{M}_{j}+\bar{M}\right)^{2}}{2 a}\right)\right]
$$

Onde,

$\bar{Y}_{i .}$ : média do $i$-ésimo genótipo em todos os ambientes: $\overline{Y_{i .}}=\sum_{i=1}^{a} Y_{i j} / a$;

$\bar{M}$ : média do genótipo $i$ mais produtivo em todos os ambientes: $\bar{M}=\sum_{j=1}^{a} \bar{M}_{j} / a$;

$\bar{M}_{j}$ : média do genótipo $i$ mais produtivo no j-ésimo ambiente;

$a$ : número de ambientes.
$\mathrm{O}$ primeiro termo da equação representa o efeito genético, enquanto que o segundo termo representa o efeito da interação G x A. Dessa forma, os genótipos mais estáveis são aqueles que apresentam as menores estimativas de $\mathrm{Pi}$, de forma que este valores sejam constituídos, em sua maior proporção, por desvios genéticos e não por desvios da interação Gx A (\%GxA).

A metodologia proposta por Eskridge (1990) ainda é relativamente desconhecida e pouco utilizada. Esta metodologia baseia-se na estimação de componentes de primeira segurança (safety first), cuja idéia original surgiu de um modelo proposto por Kataoka (1963). Este modelo foi muito utilizado por economistas em operações financeiras de alto risco, as quais requeriam a fixação de um limite mínimo de segurança na taxa de retorno de alguns investimentos, aquém do qual, elevados prejuízos poderiam ocorrer. O modelo geral pode ser expresso por:

$$
\overline{Y_{i .}}-Z_{(I-\alpha)}\left(V_{i}\right)^{1 / 2}
$$

Onde,

$\overline{Y_{i}}$ : media no genótipo $i$ no ambiente $j$;

$V_{i}$ : medida de variância em função de um percentil $1-\alpha$ de uma distribuição normal $\left(Z_{(I-\alpha)}\right)$.

Adaptando o modelo original de Kataoka (1963) para a utilização na experimentação agrícola, Eskridge (1990) simplesmente substituiu o termo representado pela medida de variância da equação por alguma medida de estabilidade, previamente definida de acordo com os conceitos de estabilidade tipo 1, 2 e 3 reportados por Lin, Binns e Lefkovitch (1986).

A estabilidade tipo 1 considera apenas a variância genética dos genótipos avaliados em ambientes contrastantes, desconsiderando, portanto, os efeitos exercidos pelo ambiente. A estabilidade tipo 2 considera a ampla adaptabilidade dos genótipos, de forma que um genótipo é considerado estável quando este apresenta resposta paralela à resposta média 
de todos os genótipos que estão sendo testados. Por sua vez, a estabilidade tipo 3 está relacionada com a previsibilidade de desempenho fenotípico dos genótipos, de forma que o genótipo mais estável é aquele que apresenta desvios da regressão em relação a um índice ambiental de baixa magnitude.

Baseado nestes conceitos de estabilidade, Eskridge (1990) descreveu diferentes parâmetros de estabilidade mediante a substituição da medida de variância do modelo de Kataoka (1963) pela variância de Shukla (1972), pela variância entre ambientes ou por componentes de regressão linear, de acordo com cada um dos parâmetros. Os parâmetros definidos foram, portanto, $E V, F W, S H$ e $E R$. Os componentes de variância incluídos em cada um dos parâmetros foram: variância entre ambientes $\left(\hat{S}_{x i}^{2}\right)$ em $E V$; o coeficiente de regressão linear de Finlay e Wilkinson $\left(\hat{\beta}_{l i}\right)$ em $F W$; a variância de Shukla $\left(\sigma_{i}\right)$ em $S H$; e o coeficiente de regressão linear de Finlay e Wilkinson $\left(\hat{\beta}_{l i}\right)$ juntamente com a variância dos desvios da regressão linear de Eberhart e Russel $\left(\hat{S}_{d i}^{2}\right)$ em $E R$. Cada parâmetro pode ser estimado pelas seguintes expressões:

$$
\begin{gathered}
\boldsymbol{E} \boldsymbol{V}=\bar{Y}_{i .}-Z_{(I-\alpha)}\left(\hat{S}_{x i}^{2}\right)^{1 / 2} \\
\boldsymbol{F} \boldsymbol{W}=\bar{Y}_{i .}-Z_{(I-\alpha)}\left[\left(\hat{\beta}_{l i}-1\right)^{2}\left(\hat{S}_{y}^{2}\right)(1-1 / a)\right]^{1 / 2} \\
\boldsymbol{S} \boldsymbol{H}=\bar{Y}_{i .}-Z_{(1-\alpha)}\left[\hat{\sigma}_{a}^{2}+\hat{\sigma}_{i}^{2}\right]^{1 / 2} \\
\boldsymbol{E} \boldsymbol{R}=\overline{\boldsymbol{Y}}_{i .}-Z_{(I-\alpha)}\left[\left(\left(\hat{\boldsymbol{\beta}}_{l i}-1\right)^{2}\left(\hat{S}_{y}^{2}\right)(1-1 / a)\right)+\left(\hat{S}_{d i}^{2}\right)\right]^{1 / 2}
\end{gathered}
$$

Onde,

$g=$ número de genótipos;

$a=$ número de ambientes;

$\hat{S}_{x i}^{2}=\sum_{j=1}^{a}\left(Y_{i j}-\bar{Y}_{i .}\right)^{2} /(a-1)$;

$\hat{S}_{y}^{2}=\sum_{j=1}^{a}\left(\bar{Y}_{. j}-\bar{Y} . .\right)^{2} /(a-1)$;

$\hat{\sigma}_{a}^{2}=[Q M(A)-Q M(G x A)] / g$;

$Q M(A)=g\left[\sum_{j=1}^{a}\left(\bar{Y}_{, j}-\bar{Y}_{. .}\right)^{2} /(a-1)\right]=g \hat{S}_{y}^{2} ;$
$Q M(G x A)=\frac{\sum_{i=1}^{g} \sum_{j=1}^{a}\left(Y_{i j}-\bar{Y}_{i .}-\bar{Y}_{. j}+\bar{Y}_{. .}\right)^{2}}{(g-1)(a-1)} ;$

$\hat{\sigma}_{i}^{2}=g \frac{\sum_{j=1}^{a}\left(Y_{i j}-\bar{Y}_{i .}-\bar{Y}_{j}+\bar{Y}\right)^{2}}{(g-2)(a-1)}-\frac{\sum_{i=1}^{g} \sum_{j=1}^{a}\left(Y_{i j}-\bar{Y}_{i .}-\bar{Y}_{j}+\overline{Y_{Y}}\right)^{2}}{(g-2)(g-1)(a-1)} ;$

$\hat{S}_{d i}^{2}=\frac{1}{(a-2)}\left[\sum_{j=1}^{a}\left(Y_{i j}-\bar{Y}_{i .}\right)^{2}-\left(\hat{\beta}_{l i}\right)^{2} \sum_{j=1}^{a}\left(\bar{Y}_{. j}-\bar{Y}\right)^{2}\right]$.

O parâmetro $E V$ foi criado para explicar a estabilidade tipo 1 (ESKIDGE, 1990). Entretanto, este parâmetro não foi abordado no presente estudo, uma vez que Eskridge (1990) cita que o mesmo possui aplicabilidade apenas na seleção de genótipos sob condições ambientais muito pouco contrastantes, o que é impossível de ser contemplado na seleção de genótipos para adaptabilidade ampla e boa previsibilidade de resposta fenotípica. Por sua vez, os parâmetros $F W$ e $S H$ proporcionam a explicação da estabilidade tipo 2, enquanto que o parâmetro $E R$ propicia o estudo dos tipos 2 e 3 de estabilidade, simultaneamente (ESKRIDGE, 1990).

Assim, os genótipos mais estáveis, de acordo com os conceitos de estabilidade de Lin, Binns e Lefkovitch (1986), serão aqueles que apresentarem maiores estimativas dos respectivos parâmetros de estabilidade propostos por Eskridge (1990), ou seja, aqueles que apresentarem o maior limite mínimo de segurança. Nesse contexto, médias fenotípicas inferiores a este limite mínimo de segurança só devem ocorrer dentro de uma probabilidade $\alpha$ de erro.

No que se refere à metodologia proposta por Annicchiarico (1992), esta é baseada em análise de variância, e compreende a estimação de um índice de confiança $\left(I_{i}(\%)\right)$ que é tomado como parâmetro de estabilidade. Este índice de confiança estima a probabilidade de cada genótipo apresentar médias superiores a um padrão fenotípico preestabelecido, o qual geralmente considera a média geral dos experimentos (NUNES et al., 1999), e pode ser expresso por: 


$$
I_{i}=\bar{Y}_{i .}-Z_{(I-\alpha)} S_{i}
$$

Onde,

$I_{i}$ : índice de confiança do genótipo $i(\%)$;

$\bar{Y}_{i .}$ : média fenotípica do genótipo $i(\%)$;

$Z_{(l-\alpha)}$ : percentil de uma distribuição normal;

$S_{i}$ : desvio padrão dos valores em porcentagem;

$\alpha$ : nível de significância.

Os genótipos que apresentarem os maiores valores de $I_{i}(\%)$ são considerados mais estáveis. Genótipos com valores de $I_{i}(\%)$ maiores que $100 \%$, teoricamente, nunca deverão apresentar medias fenotípicas inferiores à média geral dos experimentos. Uma vez que estes genótipos têm comportamento fenotípico mais previsível, eles são considerados mais estáveis.

\section{Resultados e Discussão}

A análise de variância indicou diferenças significativas $(\mathrm{p} \leq 0,05)$ para o efeito de tratamentos para produção de raízes tuberosas (Tabela 1) e índice de colheita (Tabela 2) indicando a existência de variabilidade genética considerável entre as 14 cultivares avaliadas. Também foi verificada a presença de efeito significativo da interação $G$ x A para ambas as características (dados não apresentados), o que justifica a realização de estudos de estabilidade e adaptabilidade destas características. Dessa forma, as análises de comparação entre médias foram desdobradas por ambiente, cujos resultados estão apresentados nas Tabelas 1 e 2 para os dados de produção de raízes tuberosas e índice de colheita, respectivamente.

Observou-se que as cultivares Caipira, Branca 1, Fécula Branca e Amarela 2 apresentaram as médias mais elevadas de produção de raízes tuberosas em todos os ambientes (Maringá 2001/2002, Maringá 2002/2003, Araruna 2003/2004 e Araruna 2004/2005), embora a cultivar Quarenta quilos também mereça destaque por ter apresentado médias de produção de raízes tuberosas elevadas em três dos quatro ambientes de avaliação (Tabela 1). Por sua vez, as médias de produção de raízes tuberosas mais reduzidas, nos quatro ambientes de avaliação, foram apresentadas pela cultivar Branca 3 (Tabela 1).

Tabela 1. Médias e resumo da análise de variância para a produção de raízes tuberosas de 14 cultivares de mandiocade-mesa coletadas no Estado do Paraná, e avaliadas nos municípios de Maringá (2001 a 2003) e de Campo Mourão (2003 a 2005), região Noroeste do Paraná.

\begin{tabular}{|c|c|c|c|c|c|}
\hline \multirow{3}{*}{ Cultivares } & \multicolumn{5}{|c|}{ Produção de Raízes Tuberosas (t ha ${ }^{-1}$ ) } \\
\hline & \multicolumn{2}{|c|}{ Maringá } & \multicolumn{2}{|c|}{ Campo Mourão } & \multirow{2}{*}{ Média } \\
\hline & $2001 / 2002$ & $2002 / 2003$ & $2003 / 2004$ & $2004 / 2005$ & \\
\hline Caipira & $33,69 \mathrm{a}$ & $33,01 \mathrm{a}$ & $45,90 \mathrm{a}$ & $27,00 \mathrm{a}$ & 34,90 \\
\hline Branca 1 & $30,00 \mathrm{a}$ & $30,83 \mathrm{a}$ & $46,80 \mathrm{a}$ & $19,33 \mathrm{a}$ & 31,74 \\
\hline Quarenta Quilos & $27,91 \mathrm{a}$ & $29,94 \mathrm{a}$ & $38,17 \mathrm{a}$ & $17,50 \mathrm{~b}$ & 28,38 \\
\hline Guaíra & $29,73 \mathrm{a}$ & $30,93 \mathrm{a}$ & $34,37 \mathrm{~b}$ & $16,50 \mathrm{~b}$ & 27,88 \\
\hline Amarela da Rama Branca & $29,84 \mathrm{a}$ & $16,76 \mathrm{~b}$ & $34,07 \mathrm{~b}$ & $10,50 \mathrm{~b}$ & 22,79 \\
\hline Amarela da Rama Cinza & $20,91 \mathrm{~b}$ & $13,49 \mathrm{~b}$ & $27,88 \mathrm{c}$ & $15,00 \mathrm{~b}$ & 19,32 \\
\hline Branca de Maringá & $21,09 \mathrm{~b}$ & $15,06 \mathrm{~b}$ & $24,76 \mathrm{c}$ & $12,50 \mathrm{~b}$ & 18,35 \\
\hline Branca 2 & $29,68 \mathrm{a}$ & $20,00 \mathrm{~b}$ & $31,77 \mathrm{~b}$ & $19,83 \mathrm{a}$ & 25,32 \\
\hline Amarela de São Domingos & $31,98 \mathrm{a}$ & $14,58 \mathrm{~b}$ & $26,32 \mathrm{c}$ & $12,00 \mathrm{~b}$ & 21,22 \\
\hline Branca 3 & $25,10 b$ & $18,25 \mathrm{~b}$ & $16,32 \mathrm{~d}$ & $9,83 \mathrm{~b}$ & 17,38 \\
\hline Pão & $19,19 b$ & $27,60 \mathrm{a}$ & $24,26 \mathrm{c}$ & $13,50 \mathrm{~b}$ & 21,14 \\
\hline Amarela 1 & 29,66 a & $34,76 \mathrm{a}$ & $32,94 \mathrm{~b}$ & $16,67 \mathrm{~b}$ & 28,51 \\
\hline Fécula Branca & $29,84 \mathrm{a}$ & $24,76 \mathrm{a}$ & $40,58 \mathrm{a}$ & $22,00 \mathrm{a}$ & 29,30 \\
\hline Amarela 2 & $27,47 \mathrm{a}$ & $25,65 \mathrm{a}$ & $44,60 \mathrm{a}$ & $23,50 \mathrm{a}$ & 30,31 \\
\hline $\mathrm{F}_{(\mathrm{QMT} / \mathrm{QMR})}$ & $2,88 *$ & $8,85^{*}$ & $5,93 *$ & $10,79 *$ & -- \\
\hline Média geral & 27,58 & 23,97 & 33,48 & 16,83 & 25,47 \\
\hline C.V. $(\%)$ & 16,22 & 18,12 & 19,28 & 15,93 & 18,39 \\
\hline
\end{tabular}

Médias seguidas da mesma letra na coluna não diferem entre si ( $\mathrm{p}>0,05)$ pelo teste Scott e Knott (1974); *Significativo $(\mathrm{p} \leq 0,05)$ pelo teste $\mathrm{F} .{ }^{\text {ns }}$ Não significativo. 
Quanto ao índice de colheita, as cultivares que mais se destacaram foram Branca 3 e Fécula Branca (Tabela 2), uma vez que estas cultivares apresentaram as médias mais elevadas em ambos os experimentos conduzidos em Maringá e Campo Mourão. Semelhantemente, as cultivares Amarela 2 e Amarela da Rama Branca também merecem destaque, visto que estas cultivares apresentaram índices de colheita mais elevados em pelo menos três dos quatro ambientes de avaliação. Embora a cultivar Branca 2 também tenha apresentado índice de colheita elevado em três ambientes, no experimento conduzido em Campo Mourão no ano agrícola de 2003/2004 o índice de colheita observado foi bastante reduzido (Tabela 2), o que indica que esta cultivar pode não apresentar comportamento fenotípico previsível para a característica índice de colheita, no entanto, demais considerações serão reportadas na discussão à respeito da análise de estabilidade.

Por outro lado, a cultivar Branca de Maringá apresentou o menor índice de colheita em todos os ambientes de avaliação, sendo considerada a cultivar menos promissora no que se refere à característica índice de colheita (Tabela 2).

De forma geral, as cultivares com produção de raízes tuberosas mais elevada foram a Caipira, Branca 1, Amarela 2 e Fécula Branca (Tabela 1), enquanto que para o índice de colheita as cultivares que mais se destacaram foram a Fécula Branca, a Amarela de São Domingos, a Amarela da Rama Branca e a Amarela 2 (Tabela 2).

Tabela 2. Médias e resumo da análise de variância para o índice de colheita de 14 cultivares de mandioca-de-mesa coletadas no Estado do Paraná, avaliadas nos municípios de Maringá (2001 a 2003) e de Campo Mourão (2003 a 2005), região Noroeste do Paraná.

\begin{tabular}{|c|c|c|c|c|c|}
\hline \multirow{3}{*}{ Cultivares } & \multicolumn{5}{|c|}{ Índice de Colheita (\%) } \\
\hline & \multicolumn{2}{|c|}{ Maringá } & \multicolumn{2}{|c|}{ Campo Mourão } & \multirow{2}{*}{ Média } \\
\hline & $2001 / 2002$ & $2002 / 2003$ & $2003 / 2004$ & $2004 / 2005$ & \\
\hline Caipira & $58,49 \mathrm{~b}$ & $68,26 \mathrm{a}$ & $66,34 \mathrm{c}$ & $63,18 \mathrm{a}$ & 64,07 \\
\hline Branca 1 & $68,06 \mathrm{a}$ & $70,66 \mathrm{a}$ & $75,26 \mathrm{~b}$ & $47,53 \mathrm{~b}$ & 65,38 \\
\hline Quarenta Quilos & $55,30 \mathrm{~b}$ & $65,72 \mathrm{a}$ & $65,99 \mathrm{c}$ & $58,68 \mathrm{a}$ & 61,42 \\
\hline Guaíra & $58,47 \mathrm{~b}$ & $66,49 \mathrm{a}$ & $51,14 \mathrm{~d}$ & $70,82 \mathrm{a}$ & 61,73 \\
\hline Amarela da Rama Branca & $64,11 \mathrm{a}$ & $66,26 \mathrm{a}$ & $70,13 \mathrm{~b}$ & $68,15 \mathrm{a}$ & 67,16 \\
\hline Amarela da Rama Cinza & $55,93 \mathrm{~b}$ & $64,45 \mathrm{a}$ & $58,89 \mathrm{~d}$ & $58,14 \mathrm{a}$ & 59,35 \\
\hline Branca de Maringá & $43,11 \mathrm{c}$ & $55,98 \mathrm{~b}$ & $52,60 \mathrm{~d}$ & $53,00 \mathrm{~b}$ & 51,17 \\
\hline Branca 2 & $63,29 \mathrm{a}$ & $65,27 \mathrm{a}$ & $57,74 \mathrm{~d}$ & $64,61 \mathrm{a}$ & 62,72 \\
\hline Amarela de São Domingos & $70,13 \mathrm{a}$ & $70,60 \mathrm{a}$ & $75,52 \mathrm{~b}$ & $54,91 \mathrm{~b}$ & 67,79 \\
\hline Branca 3 & $65,58 \mathrm{a}$ & $74,97 \mathrm{a}$ & $85,01 \mathrm{a}$ & $61,37 \mathrm{a}$ & 71,48 \\
\hline Pão & $37,20 \mathrm{c}$ & $56,28 \mathrm{~b}$ & $81,72 \mathrm{a}$ & $60,46 \mathrm{a}$ & 58,91 \\
\hline Amarela 1 & $61,44 \mathrm{~b}$ & $67,30 \mathrm{a}$ & $61,32 \mathrm{c}$ & $50,34 \mathrm{~b}$ & 60,10 \\
\hline Fécula Branca & $69,62 \mathrm{a}$ & $73,20 \mathrm{a}$ & $80,25 \mathrm{a}$ & $64,25 \mathrm{a}$ & 71,83 \\
\hline Amarela 2 & $54,66 \mathrm{~b}$ & $40,15 \mathrm{a}$ & 84,89 a & $58,49 \mathrm{a}$ & 67,05 \\
\hline $\mathrm{F}_{(\mathrm{QMT} / \mathrm{QMR})}$ & $20,57 *$ & $4,38 *$ & $10,62 *$ & $4,55^{*}$ & -- \\
\hline Média geral & 58,89 & 66,83 & 69,06 & 59,57 & 63,58 \\
\hline C.V. $(\%)$ & 6,15 & 6,76 & 8,99 & 8,98 & 7,89 \\
\hline
\end{tabular}

Médias seguidas da mesma letra na coluna não diferem entre si ( $\mathrm{p}>0,05)$ pelo teste Scott e Knott (1974); *Significativo $(\mathrm{p} \leq 0,05)$ pelo teste F. ${ }^{\text {ns }}$ Não significativo. 
No que se refere à avaliação da estabilidade de produção de raízes tuberosas, a metodologia de Lin e Binns (1988) indicou que as cultivares Caipira, Branca 1, Amarela 2, Fécula Branca e Quarenta Quilos foram as mais estáveis (Tabela 3). Entretanto, a cultivar Guaíra também merece destaque quanto à estabilidade de produção de raízes tuberosas, uma vez que esta cultivar apresentou baixos valores para os parâmetros $P_{i}$ e $\% G x A$ (Tabela 3). Conforme Lin e Binns (1988), ambos os parâmetros $\left(P_{i}\right.$ e \%GxA) são levados em consideração na análise da estabilidade, de forma que os genótipos mais estáveis são aqueles que apresentam baixa estimativa de $P_{i}$, e que este valor de $P_{i}$ seja constituído, em sua maior proporção, de desvio genético e não de desvio decorrente da interação entre genótipos e ambientes (\%GxA). É importante salientar que, embora as cultivares Amarela da Rama Cinza e Branca de Maringá tenham apresentado baixas estimativas do parâmetro $\% G x A$, estas cultivares apresentaram valores de $P_{i}$ muito elevados e, portanto, não são consideradas estáveis (Tabela 3). Por sua vez, a Branca 3 foi classificada como a cultivar mais instável para a característica produção de raízes tuberosas, visto que ela apresentou a maior estimativa de $P_{i}$ aliada à elevada estimativa do parâmetro \%GxA (Tabela 3).

Com relação à metodologia proposta por Eskridge (1990), pode-se observar na Tabela 3 que a cultivar Caipira apresentou maior estabilidade tipo 2 para produção de raízes tuberosas. Isso indica que esta cultivar tende a apresentar resposta paralela à resposta média do conjunto genotípico estudado. Além disso, como as estimativas dos parâmetros de estabilidade $F W$ e $S H$ representam o limite mínimo de segurança na expressão fenotípica da característica em questão, a cultivar Caipira não deverá apresentar médias de produtividade de raízes tuberosas inferiores a 22,90 $\mathrm{tha}^{-1}(\mathrm{SH}=22,90)$, salvo dentro de uma probabilidade $\alpha(0,05)$ de erro. No entanto, as cultivares Fécula Branca, Amarela 2, Branca 1, Quarenta Quilos e Guaíra também merecem destaque por terem apresentado baixas estimativas de $F W$ e $S H$ (Tabela 3) tendo, portanto, apresentado estabilidade tipo 2 satisfatória para a característica produção de raízes tuberosas. Em contraste, as cultivares mais instáveis foram Branca 3 e Branca de Maringá (Tabela 3).

Tabela 3. Estimativa dos parâmetros de estabilidade para Produção de Raízes Tuberosas de 14 cultivares de mandiocade-mesa coletadas no Estado do Paraná, conforme as metodologias propostas por Lin e Binns (1988), por Eskridge (1990) e por Annicchiarico (1992)

\begin{tabular}{|c|c|c|c|c|c|c|c|}
\hline \multirow[b]{2}{*}{ Cultivares } & \multicolumn{3}{|c|}{ Lin e Binns } & \multicolumn{3}{|c|}{ Eskridge } & \multirow{2}{*}{$\begin{array}{c}\text { Annicchiarico } \\
I_{i}(\%)\end{array}$} \\
\hline & $P_{i}$ & $\begin{array}{c}\text { Desvio } \\
\text { Genético }\end{array}$ & $\% G x A$ & $F W$ & $S H$ & $E R$ & \\
\hline Caipira & $0,485_{(1)}$ & 0,220 & 0,265 & $34,139_{(1)}$ & $22,900_{(1)}$ & $32,657_{(1)}$ & $135,028_{(1)}$ \\
\hline Branca 1 & $10,990_{(2)}$ & 7,312 & 3,677 & 26,280 & $17,404_{(2)}$ & 25,600 & 119,192 \\
\hline Quarenta Quilos & $27,665(5)$ & 25,789 & 1,876 & $26,769(6)$ & 16,225 & 25,700 & 108,078 \\
\hline Guaíra & 36,905 (6) & 29,497 & 7,408 & 27,603 & $15,451_{(6)}$ & $25,245(6)$ & 105,631 \\
\hline Amarela da Rama Branca & 96,633 & 81,529 & 15,104 & 17,683 & 8,832 & 17,051 & 79,339 \\
\hline Amarela da Rama Cinza & 139,750 & 131,942 & 7,808 & 17,446 & $6,578(11)$ & $16,016_{(11)}$ & $72,201(12)$ \\
\hline Branca de Maringá & 155,383 & 148,119 & 7,264 & $16,110_{(13)}$ & 6,648 & $15,803(12)$ & 70,196 \\
\hline Branca 2 & 63,921 & 52,461 & 11,460 & 23,327 & $12,827_{(8)}$ & $22,177_{(8)}$ & 96,842 \\
\hline Amarela de São Domingos & 131,836 & 102,873 & 28,962 & 20,699 & 5,787 & $16,219_{(10)}$ & 75,108 \\
\hline Branca 3 & 196,260 & 165,387 & 30,873 & 12,343 & 1,591 & 10,737 & 63,447 \\
\hline Pão & $119,008_{(10)}$ & 104,073 & 14,936 & $16,480_{(12)}$ & $5,888_{(12)}$ & 14,967 & $78,594(10)$ \\
\hline Amarela 1 & $39,411_{(7)}$ & 24,907 & 14,504 & $27,506_{(5)}$ & 13,985 (7) & $24,074_{(7)}$ & $106,445(6)$ \\
\hline Fécula Branca & 22,322 & 19,645 & 2,676 & $28,211_{(3)}$ & 17,139 & 26,798 & 112,441 \\
\hline Amarela 2 & $17,353(3)$ & 13,823 & 3,530 & $28,338_{(2)}$ & $16,036_{(5)}$ & 25,833 (3) & 114,518 \\
\hline
\end{tabular}

Os valores dentro dos parênteses indicam o ranking da estabilidade em ordem decrescente; $P_{i}=$ parâmetro de estabilidade fenotípica, que é desdobrado em Desvio Genético e \%GxA; FW = índice de primeira segurança com o coeficiente de regressão linear de Finlay e Wilkinson como medida de estabilidade; $S H$ = índice de primeira segurança com a variância de Shukla como medida de estabilidade; $E R=$ índice de primeira segurança com o coeficiente de regressão linear de Finlay e Wilkinson e a variância dos desvios da regressão linear como medidas de estabilidade; $I_{i}(\%)$ = índice de confiança como parâmetro de estabilidade. 
Considerando os tipos 2 e 3 de estabilidade, reportados por Lin, Binns e Lefkovitch (1986), a metodologia de Eskridge (1990) permitiu verificar que a cultivar que apresentou maior estabilidade de produção de raízes tuberosas foi a Caipira, seguida das cultivares Fécula Branca, Amarela 2, Quarenta Quilos, Branca 1 e Guaíra, dadas as estimativas mais elevadas do parâmetro ER observadas (Tabela 3). Ou seja, respeitada uma probabilidade de $5 \%$ de erros casuais $(\alpha)$, a cultivar Caipira não deve apresentar produtividade média de raízes tuberosas inferior a 32,65 t ha $^{-1}$, mesmo quando cultivada sob condições ambientais diferentes daquelas à que foi submetida durante o período de condução deste estudo. Da mesma forma, as cultivares Fécula Branca, Amarela 2, Quarenta Quilos, Branca 1 e Guaíra não deverão apresentar médias de produtividade inferiores a 26,79, $25,83,25,70,25,60$ e $25,24 \mathrm{tha}^{-1}$, respectivamente. Por sua vez, a cultivar Branca 3 foi a que apresentou maior instabilidade de produção de raízes tuberosas, visto que esta cultivar apresentou a menor estimativa do parâmetro $E R\left(10,73 \mathrm{t} \mathrm{ha}^{-1}\right)$.

Concernente à metodologia de Annicchiarico (1992), observou-se que a cultivar Caipira apresentou o índice de confiança mais elevado $(135,028 \%) \mathrm{em}$ relação ao restante do conjunto genotípico avaliado. Visto que este índice de confiança representa a probabilidade do $i$-ésimo genótipo não apresentar rendimento inferior a um padrão convenientemente escolhido, que neste estudo foi a média geral $(25,47$ $\mathrm{t} \mathrm{ha}^{-1}$ ), pode-se inferir que a cultivar Caipira apresentou maior estabilidade de produção de raízes tuberosas. Vale ressaltar que Nunes et al. (1999) reportaram que os genótipos com estimativas do parâmetro $I_{i}(\%)$ superiores a $100 \%$ representam os genótipos mais previsíveis ou mais estáveis. Ou seja, se o índice de confiança estimado for superior a 100\%, não há perspectiva da cultivar apresentar produtividade de raízes tuberosas inferior à média geral $\left(25,47 \mathrm{t} \mathrm{ha}^{-1}\right)$. Portanto, as cultivares Branca 1, Amarela 2, Fécula Branca, Quarenta Quilos, Amarela 1 e Guaíra também podem ser consideradas estáveis para produção de raízes tuberosas, enquanto que a cultivar Branca 3 mostrou-se a mais instável.
Em relação à característica índice de colheita (Tabela 4), a cultivar Fécula Branca mostrou maior estabilidade, seguida pelas cultivares Branca 3, Amarela da Rama Branca, Caipira, Amarela de São Domingos e Amarela 2, respectivamente, visto que estas cultivares apresentaram estimativas reduzidas dos parâmetros $P_{i}$ e \%GxA. Entretanto, embora as cultivares Quarenta Quilos, Amarela da Rama Cinza e Branca de Maringá tenham apresentado estimativas reduzidas do parâmetro $\% G x A$, estas cultivares apresentaram elevada estimativa de $P_{i}$, mostrandose, portanto, fenotipicamente instáveis. Por sua vez, as cultivares Pão e Guaíra apresentaram a maior instabilidade para índice de colheita em relação ao conjunto genotípico avaliado.

No que se refere à metodologia de Eskridge (1990), as cultivares Fécula Branca, Branca 3, Amarela da Rama Branca, Amarela de São Domingos e Caipira apresentaram maior estabilidade do tipo 2 para índice de colheita (Tabela 4). Isto fica evidente pelas estimativas mais elevadas dos parâmetros $F W$ e $S H$ apresentadas por estas cultivares. De acordo com Lin, Binns e Lefkovitch (1986), estas cultivares apresentam resposta semelhante à resposta média do conjunto genotípico avaliado nos diversos ambientes onde foi conduzido o presente estudo. Por outro lado, considerando os tipos 2 e 3 de estabilidade reportados por Lin, Binns e Lefkovitch (1986), pode-se observar na Tabela 4 que a cultivar mais estável foi a Fécula Branca tendo apresentado estimativa do parâmetro $E R$ igual a $69,01 \%$. Ou seja, mesmo que a cultivar Fécula Branca seja cultivada em ambientes contrastantes daqueles onde o presente estudo foi conduzido, ela deverá apresentar índice de colheita médio superior a $69 \%$. Além da cultivar Fécula Branca, as cultivares Branca 3, Amarela de São Domingos, Amarela da Rama Branca e Caipira mostraram boa estabilidade, tendo apresentado índices de colheita superiores a $61 \%$. Uma vez que o parâmetro $E R$ integra tanto o conceito da estabilidade tipo 2 quanto do tipo 3, estas cultivares podem ser classificadas como genótipos de ampla adaptabilidade e de boa previsibilidade 
Tabela 4. Estimativa dos parâmetros de estabilidade para Índice de Colheita de 14 cultivares de mandioca-de-mesa coletadas no Estado do Paraná, conforme as metodologias propostas por Lin e Binns (1988), por Eskridge (1990) e por Annicchiarico (1992)

\begin{tabular}{|c|c|c|c|c|c|c|c|}
\hline \multirow[b]{2}{*}{ Cultivares } & \multicolumn{3}{|c|}{ Lin e Binns } & \multicolumn{3}{|c|}{ Eskridge } & \multirow{2}{*}{$\begin{array}{c}\text { Annicchiarico } \\
I_{i}(\%)\end{array}$} \\
\hline & $P_{i}$ & $\begin{array}{c}\text { Desvio } \\
\text { Genético }\end{array}$ & $\% G x A$ & $F W$ & $S H$ & $E R$ & \\
\hline Caipira & $73,406_{(6)}$ & 62,288 & 11,118 & $61,945_{(5)}$ & $55,771_{(4)}$ & $61,255_{(5)}$ & $99,742_{(6)}$ \\
\hline Branca 1 & $82,517_{(7)}$ & 48,551 & 33,966 & $60,590_{(7)}$ & $47,231_{(11)}$ & $56,660_{(7)}$ & $98,232_{(7)}$ \\
\hline Quarenta Quilos & $101,813_{(8)}$ & 95,340 & 6,473 & $61,421_{(6)}$ & $54,223_{(5)}$ & $60,300_{(6)}$ & $95,970_{(9)}$ \\
\hline Guaíra & $169,374_{(12)}$ & 91,168 & 78,206 & $48,525_{(13)}$ & $39,304_{(13)}$ & $47,095_{(12)}$ & $92,905_{(10)}$ \\
\hline Amarela da Rama Branca & $42,573(3)$ & 32,547 & 10,026 & 62,059 & $57,166_{(3)}$ & 61,784 & $104,092(3)$ \\
\hline Amarela da Rama Cinza & $144,363_{(10)}$ & 126,038 & 18,326 & $55,294(10)$ & $49,523(8)$ & $54,679(10)$ & $92,038_{(11)}$ \\
\hline Branca de Maringá & 307,265 & 289,389 & 17,876 & 48,882 & $40,518_{(12)}$ & 46,933 (13) & $78,571_{(14)}$ \\
\hline Branca 2 & 115,395 & 78,196 & 37,199 & 52,715 & $47,645(10)$ & 52,445 & 96,148 \\
\hline Amarela de São Domingos & 45,249 & 27,663 & 17,586 & $66,539(2)$ & $54,143(6)$ & $62,214_{(3)}$ & $103,529_{(4)}$ \\
\hline Branca 3 & $15,013(2)$ & 7,033 & 7,980 & 64,089 & $58,892(2)$ & $63,700_{(2)}$ & $109,710_{(2)}$ \\
\hline Pão & 193,961 & 133,124 & 60,838 & 46,547 & 31,793 & $43,111_{(14)}$ & $85,346_{(13)}$ \\
\hline Amarela 1 & $139,340_{(11)}$ & 114,484 & 24,856 & $58,642_{(8)}$ & $47,671_{(9)}$ & 55,133 & $92,006_{(12)}$ \\
\hline Fécula Branca & 8,639 & 5,778 & 2,861 & $70,654(1)$ & 62,959 (1) & $69,013(1)$ & $111,585_{(1)}$ \\
\hline Amarela 2 & 51,819 & 33,495 & 18,324 & 55,772 & 49,992 & $55,332(8)$ & 101,143 \\
\hline
\end{tabular}

Os valores dentro dos parênteses indicam o ranking da estabilidade em ordem decrescente; $P_{i}=$ parâmetro de estabilidade fenotípica, que é desdobrado em Desvio Genético e \%GxA; FW= índice de primeira segurança com o coeficiente de regressão linear de Finlay e Wilkinson como medida de estabilidade; $S H$ = índice de primeira segurança com a variância de Shukla como medida de estabilidade; $E R=$ índice de primeira segurança com o coeficiente de regressão linear de Finlay e Wilkinson e a variância dos desvios da regressão linear como medidas de estabilidade; $I_{i}(\%)$ = índice de confiança como parâmetro de estabilidade.

(estáveis) para a característica índice de colheita. Por outro lado, as cultivares Pão, Branca de Maringá, Guaíra e Branca 2 apresentaram índices de colheita mais instáveis, ou imprevisíveis, visto que estas cultivares apresentaram as menores estimativas do parâmetro $E R$.

Conforme a metodologia de Annicchiarico (1992), a cultivar Fécula Branca foi a que apresentou maior estabilidade para índice de colheita dentre o conjunto genotípico avaliado (111,59\%), embora as cultivares Branca 3, Amarela da Rama Branca, Amarela de São Domingos e Amarela 2 também tenham apresentado estimativas de $I_{i}(\%)$ superiores a $100 \%$ sendo, portanto, também classificadas como estáveis. Por sua vez, as cultivares Branca de Maringá e Pão se mostraram as mais instáveis para a característica índice de colheita, visto que apresentaram as menores estimativas do parâmetro $I_{i}(\%)$.

Embora a produção de raízes tuberosas seja a característica que sempre recebe enfoque principal na cultura da mandioca, o índice de colheita pode ser utilizado como um caráter auxiliar na seleção para estabilidade fenotípica na cultura da mandioca, uma vez que o mesmo é calculado pela razão entre a produção de raízes tuberosas e o peso total da planta. É importante ressaltar que no melhoramento da mandioca, além da produtividade de raízes tuberosas, deve-se tentar associar adaptabilidade ampla, elevada estabilidade e resistência às doenças nas novas cultivares. Valle et al. (2004) comentam, ainda, que o programa de melhoramento também deve ser direcionado para a obtenção de cultivares com baixo teor de $\mathrm{HCN}$, elevado teor de amido nas raízes tuberosas e um reduzido tempo de cozimento, quando se visa o desenvolvimento de variedades para o consumo das raízes tuberosas na forma in natura.

Dessa forma, e considerando os resultados observados para todas as metodologias de análise da estabilidade fenotípica, pode-se inferir que as cultivares Caipira, Fécula Branca e Amarela 2 foram as que mais se destacaram. Além da elevada estabilidade, estas três cultivares apresentaram elevada média de produção de raízes tuberosas e elevados índices de colheita, além de apresentarem outras características peculiares de elevada importância na cultura da mandioca para o consumo das raízes tuberosas na forma in natura. Estas 
cultivares apresentam resistência à bacteriose e ao superalongamento, tempo de cozimento rápido a moderado, baixos níveis de $\mathrm{HCN}$ na polpa crua das raízes tuberosas, além de elevados teores de matéria e de amido nas raízes tuberosas (RIMOLDI et al., 2006). Em relação ao tempo de cozimento, a cultivar Caipira apresenta um tempo médio de cozimento de raízes tuberosas pouco acima de 19 minutos, enquanto que as cultivares Amarela 2 e Fécula Branca este tempo é um pouco mais de 20 e de 24 minutos, respectivamente (RIMOLDI et al., 2006). Além disso, os níveis de $\mathrm{HCN}$ reportados estiveram dentro dos limites de segurança (inferiores a $100 \mathrm{mg} \mathrm{kg}^{-1}$ ), com a cultivar Fécula Branca apresentando o nível médio mais elevado dentre estas três cultivares, que foi de $75,76 \mathrm{mg} \mathrm{kg}^{-1}$. Por sua vez, os teores médios de amido nas raízes tuberosas variaram entre $29,8 \%$ e $31,1 \%$ entre estas três cultivares (RIMOLDI et al., 2006).

Embora a cultivar Fécula Branca tenha sido inicialmente indicada por Vidigal Filho et al. (2000) para a produção comercial destinada ao abastecimento das indústrias de farinha e de fécula da região Noroeste do Estado do Paraná, onde é atualmente uma das mais cultivadas, a mesma se mostrou também apta para a exploração como mandioca-de-mesa e, assim, destinada também à alimentação humana, conforme já vem sendo utilizada por alguns pequenos agricultores do Paraná.

\section{Conclusão}

As cultivares Caipira, Fécula Branca e Amarela 2 mostraram-se mais estáveis, além de terem apresentado médias elevadas de produção de raízes tuberosas e de índice de colheita. Essas cultivares são indicadas para o consumo in natura também por apresentarem baixos níveis de HCN na polpa crua das raízes tuberosas, reduzido tempo de cozimento e elevado teor de amido nas raízes tuberosas.

\section{Agradecimentos}

Os autores agradecem à Fundação Araucária, à Capes e ao CNPq pelo apoio financeiro, o qual foi essencial para o desenvolvimento deste trabalho.

\section{Referências}

ANNICCHIARICO, P. Cultivar adaptation and recommendation from alfafa trials in Northern Italy. Journal of Genetics \& Breeding, Roma, v.46, n.1, p.26978, 1992.

ASSOCIAÇÃO BRASILEIRA DE PRODUTORES DE AMIDO DE MANDIOCA - ABAM. Escassez de raiz provoca aumento do preço da fécula. Disponível em: <http://www.abam.com.br/not.php?id=23>. Acesso em: 13 out. 2006.

EBERHART, S. A.; RUSSEL, W. A. Stability parameters for comparing varieties. Crop Science, Madison, v.6, n.1, p.36-40, 1966.

EMBRAPA. Sistema brasileiro de classificação de solo. Rio de Janeiro: CNPS, 1999.

ESKRIDGE, K. M. Selection of stable cultivars using a safety-first rule. Crop Science, Madison, v.30, p.369-374, 1990.

FINLAY, K. W.; WILKINSON, G. N. The analysis of adaptation in a plant-breeding program. Australian Journal Agriculture Research, Victoria, v.14, n. 6, p.742754, 1963.

FONSECA JÚNIOR, N. S.; GROXKO, M.; RODANTE, A.; TAKAHASHI, M.; PEQUENO, M. G.; VIDIGAL FILHO, P. S. Cadeia produtiva da mandioca no Paraná: diagnóstico e demandas atuais. Londrina: IAPAR, 2002.

FUKUDA, W. M. G. Melhoramento genético de mandioca para adaptação em diferentes ecossistemas. Cruz das Almas: Embrapa, 1986.

FUKUDA, W. M. G.; IGLESIAS, C.; SILVA, S. O. Melhoramento de mandioca. Cruz das Almas: Embrapa, 2003. (Documento, n.104).

GODOY, H.; CORREA, A. R.; SANTOS, D. Clima no Paraná. In: INSTITUTO AGRONOMICO DO PARANÁ - IAPAR. Manual agropecuário para o Paraná. Londrina: Iapar, 1976. p.17-36.

KATAOKA, S. A stochastic programming model. Econometrica, Chicago, v.31, n.1-2, p.181-196, 1963. 
KAWANO, K.; AMAYA, A.; DAZA, P.; RIOS, M. Factors affecting efficiency of hybridization and selection in cassava. Crop Science, Madison, v.18, n.3, p.373-376, 1978.

KVITSCHAL, M. V.; VIDIGAL FILHO, P. S.; PEQUENO, M. G.; SAGRILO, E.; BRUMETTI, C. C.; MANZOTTI, M.; BEVILAQUA, G. Avaliação de clones de mandioca (Manihot esculenta Crantz) para indústria na região noroeste do estado do Paraná. Acta Scientiarum: Agronomy, Maringá, v.25, n.2, p.299-304, 2003.

KVITSCHAL, M. V.; VIDIGAL FILHO, P. S.; SCAPIM, C. A.; GONÇALVES-VIDIGAL, M. C.; PEQUENO, M. G.; SAGRILO, E.; RIMOLDI, F. Phenotypic stability evaluation of cassava clones in Northwestern region of Paraná State by AMMI analysis. Crop Breeding and Applied Biotechnology, Londrina, v.7, 2007. (Prelo).

LIN, C. S.; BINNS, M. R. A superiority measure of cultivar performance for cultivar x location data. Canadian Journal of Plant Science, Ottawa, v.68, n.1, p.193-198, Jan. 1988.

LIN, C. S.; BINNS, M. R.; LEFKOVITCH, L. P. Stability analysis: where do we stand? Crop Science, Madison, v.26, p.894-900, 1986.

LORENZI, J. O. Mandioca. Campinas: CATI, 2003. (Boletim Técnico, n.245).

LORENZI, J. O.; DIAS, C. A. Cultura da mandioca. Campinas: CATI, 1993. (Boletim Técnico, 211).

MIRANDA, L. A. Características tecnológicas, agronômicas e de qualidade de mandioca-de-mesa. 2000. Tese (Doutorado em Ciência de Alimentos) - Universidade Estadual de Londrina, Londrina.

MONTALVÁN, R.; FARIA, R. T. Variabilidade genética e germoplasma. In: DESTRO, D.; MONTALVÁN, R. (Org.). Melhoramento genético de plantas. Londrina: UEL, 1999. p.27-38.

NUNES, G. H. S.; ELIAS, H. T.; HEMP, S.; SOUZA, M. A. Estabilidade de cultivares de feijão-comum no estado de Santa Catarina. Revista Ceres, Viçosa, v.46, n.268, p.625633, 1999.

OTSUBO, A. A.; MERCANTE, F. M.; MARTINS, C. S. Aspectos do cultivo da mandioca em Mato Grosso do Sul. Campo Grande: UNIDERP, 2002. p.109-125.
PIMENTEL GOMES, F. Curso de estatística experimental. Piracicaba: Nobel, 1990.

RIMOLDI, F.; VIDIGAL FILHO, P. S.; GONÇALVESVIDIGAL, M. C.; AMARAL JUNIOR, A. T.; MAIA, R. R.; KVITSCHAL, M. V.; SAGRILO, E. Yield stability in cassava (Manihot esculenta, Crantz) cultivars in the north and northwest regions of Paraná State. Crop Breeding and Applied Biotechnology, Londrina, v.2, n.2, p.197-204, 2002.

RIMOLDI, F.; VIDIGAL FILHO, P. S.; GONÇALVESVIDIGAL, M. C.; CLEMENTE, E.; PEQUENO, M. G.; MIRANDA, L.; KVITSCHAL, M. V. Produtividade, composição química e tempo de cozimento de cultivares de mandioca-de-mesa coletadas no estado do Paraná. Acta Scientiarum: Agronomy, Maringá, v.28, n.1, p.63-69, 2006.

RIMOLDI, F.; VIDIGAL FILHO, P. S.; GONÇALVESVIDIGAL, M. C.; PEQUENO, M. G.; BARELLI, M. A. A.; KVITSCHAL, M. V.; MANZOTI, M. S. Avaliação de cultivares de mandioca nos municípios de Maringá e de Rolândia no Estado do Paraná. Acta Scientiarum: Agronomy, Maringá, v.25, n.2, p.459-465, 2003a.

Stability in cassava (Manihot esculenta Crantz) cultivar yield in Paraná State. Acta Scientiarum: Agronomy, Maringá, v.25, n.2, p.467-472, 2003b.

SCOTT, A. J.; KNOTT, M. A. A cluster analysis method for grouping means in the analysis of variance. Biometrics, Washington, v.30, n.3, p.507-512, 1974.

SHUKLA, G. K. An invariant test for the homogeneity of variances in a two-way classification. Biometrics, Washington, v.28, n.4, p.1063-1072, 1972.

VALLE, T. L.; CARVALHO, C. R. L.; RAMOS, M. T. B.; MÜHLEN, G. S.; VILLELA, O. V. Conteúdo cianogênico em progênies de mandioca originadas do cruzamento de variedades mansas e bravas. Bragantia, Campinas, v.63, n.2, p.221-226, 2004.

VIDIGAL FILHO, P. S.; PEQUENO, M. G.; SCAPIM, C. A.; GONÇALVES VIDIGAL, M. C.; MAIA, R. R.; SAGRILO, E.; SIMON, G. A.; LIMA, R. S. Avaliação de cultivares de mandioca na região noroeste do Paraná. Bragantia, Campinas, v.59, n.1, p.69-75, 2000. 